\title{
Exploring the Mode Change Behavior of Park-and-Ride Users
}

\author{
Shahi Taphsir Islam, ${ }^{1}$ Zhiyuan Liu, ${ }^{1}$ Majid Sarvi, ${ }^{1}$ and Ting $\mathrm{Zhu}^{2}$ \\ ${ }^{1}$ Institute of Transport Studies, Department of Civil Engineering, Monash University, Clayton, VIC 3800, Australia \\ ${ }^{2}$ School of Transportation, Southeast University, Nanjing 210096, China \\ Correspondence should be addressed to Zhiyuan Liu; zhiyuan.liu@monash.edu
}

Received 20 November 2014; Accepted 19 May 2015

Academic Editor: Guangming Xie

Copyright ( 2015 Shahi Taphsir Islam et al. This is an open access article distributed under the Creative Commons Attribution License, which permits unrestricted use, distribution, and reproduction in any medium, provided the original work is properly cited.

\begin{abstract}
This paper investigates the mode change behavior of park-and-ride $(\mathrm{P} \& \mathrm{R})$ users, which is of considerable significance to analyze the effectiveness of P\&R site on the commuters' travel mode change as well as the increase of public transport mode share. Data from an intercept interview survey conducted at different P\&R facilities in Metropolitan Melbourne is used. A questionnaire containing revealed preference (RP) and stated preference (SP) questions is used to interview the individuals who park at the facility and catch public transport to go to city. This study firstly aims to know the factors affecting current travel behavior using RP data and secondly to investigate the importance of the factors on influencing the commuters' decision of travel mode choice using the SP data. The empirical models using multinomial logistic regression reveal that travel time taken by transit vehicle and transfer time at $\mathrm{P} \& \mathrm{R}$ stations are the primary factors affecting individuals' decision on choosing public transport whereas parking fare is the additional factor affecting commuters' choice of driving. Based on the results of this study, the effectiveness of P\&R scheme on commuters' travel mode change is evaluated which would be helpful to shed lights on the future construction of P\&R sites.
\end{abstract}

\section{Introduction}

Modern cities have been suffering immensely from the traffic congestion induced with the proliferation of private vehicles on road network. Due to the limited capacity of transportation infrastructure, this traffic related congestions and associated environmental pollution as a result of gas emissions have been deteriorating the quality of life and safety in urban city of many modern metropolises. Consequently, tackling such congestion issues has been a dominant theme of concern in transport research since the mass adoption of the automobile and as a result, most countries around the world are now turning to traffic management systems to cope with the congestion [1].

Transit has been promoted in many cities around the world to facilitate people's travel needs [2]. It has been considered an effective way to mitigate the growing traffic congestion by encouraging the public transport use upon implementation of the congestion pricing regimes to increase network users' travel cost of using private cars in $\mathrm{CBD}$ area [3]. Hence, public transport facilities have been viewed by the transport engineers, transit operators, or urban planners as a solution to the traffic congestion related problems. Eventually the consideration of various forms of public transportation, increase in the coverage of public transport systems, high passenger ridership, and affordable fare structure have been regarded as a measure to increase the public transportation usage [4]. Park-and-Ride (P\&R) has been used as a means of travel demand management throughout many western countries since the 1930s [5]. P\&R is defined as an operation in which commuters, travelling by private vehicle either as drivers or as passengers, gather at a common site where they transfer to higher-occupancy vehicles, that is, light or heavy trains, buses, and tram [5], to complete their journeys to work. P\&R sites are mainly car parks at which users can transfer to public transportation to reach their final destination [6].

As widely established in many western countries, $\mathrm{P} \& \mathrm{R}$ is becoming a one of the most essential components of congestion management scheme with the objective of increasing the mode share of public transport that subsequently results in a more sustainable metropolitan transport system. P\&R aims to influence the travelers' attitudes and behavior into shifting from private vehicle use to mix mode of transport, that is, 
private vehicle and public transport. However, there has been a dispute on the role of $P \& R$ scheme in increasing public transport use, thus reducing vehicle use on road. Despite the critical impact of P\&R scheme on commuters' behavior, no studies systematically analyze the effectiveness of $P \& R$ site on the users' travel mode change.

This paper aims to address this gap in research by exploring the factors that determine the choice of using $\mathrm{P} \& \mathrm{R}$ and comparing them with other modes of transport. It documents the mode change behavior of travelers using $\mathrm{P} \& \mathrm{R}$ service. In the context of this, an intercept interview survey has been conducted at different P\&R stations' car parks in Melbourne. Multinomial logistic regression was used to investigate the factors affecting the mode change behavior of commuters; however aspects of the findings would be useful for the government to take cautionary steps to reduce the obstacles that stop commuters from using such sustainable transport mode. The paper commences with a summary of relevant literature. Survey methodology and approaches are then described including the categories of questions asked. This is followed by a presentation of the results and their implications. Finally a conclusion, including a discussion of future direction of research in this field, is offered.

\section{Literature Review}

The continuous traffic growth in mega cities has imposed challenges in achieving sustainable urban development [7]. However, network capacity expansion through new road construction has never been a sustainable solution to traffic congestion, because of the limited land space especially in urban area, and also because new or widened road will attract more traffic demand, thus causing unwanted congestion in the unchanged connection roads. Targeting at the sustainable development of transport systems, prompting the usage of public transport, that is, bus, train, and tram, has been regarded as a universal solution because the spatial efficiency of public transport is much higher and also its average fuel consumption rate as well as emission rate is less than one tenth of road traffic [8].

Public transport system is not much attractive to commuters living in suburb and travelling to city because of inconvenience of taking public transport in the very beginning of their journey due to much longer trip time, lack of door-to-door service, troublesome public transport itinerary, and low bus frequency. P\&R service, therefore, becomes an integral part of demand management and congestion mitigation scheme.

In spite of the practical significance of $P \& R$ scheme, there is no direct research literature analyzing the effectiveness of $P \& R$ site on the commuters' travel mode change as well as the increase of public transport mode share. Therefore this literature review has had to draw on transport research which partially concerns the effect of P\&R on modal shift and few behavioral case studies' results and some references on logistic regression used in choice and behavior studies in literature. It begins with a review of worldwide P\&R approach, few case studies' results concerning the choice behavior and demand of P\&R. Next, research related to
P\&R behavior modelling is discussed. Finally a discussion on regression method used in the paper is used.

2.1. Overview of $P \& R$ Worldwide. As a result of the city and federal transportation officials' recognition of the need to plan for coordinated, continuous, and comprehensive urban transportation modes, P\&R scheme has gained enormous popularity since its introduction during the 1930s in USA [5].

Bus-based P\&R scheme had been initiated during 1960s and 1970s in UK as a solution to infrastructural capacity constraints [9]. In spite of the UK government's withdrawal of political support for P\&R scheme as there was conflict in understanding its role of reducing car usage, the local authorities had continued to adopt the scheme by considering it as a positive option for them.

Since the success of the first trial of P\&R facility at Kowloon-Canton Railway Corporation (KCRC) rail network, Sheung Shui in Hong Kong in 1997, the scheme has been in operation [10]. The Transport Department and the KCRC collaboratively provided the financial incentive for the use of this P\&R facility which benefitted them by the resulting induction of modal shift from private vehicle to rail mode, thus reducing the number of private vehicles on the roads and traffic congestion levels and increasing patronage for the KCRC. China is in the beginning phase in terms of P\&R schemes that is Beijing and Shanghai recently conducted pilot studies on the feasibility of P\&R facilities [2].

$\mathrm{P} \& \mathrm{R}$ plays an important role in Australian transportation system for over 40 years [11]. It has become an important scheme to prompt the public transport usage in Australian cities. Rail-based P\&R system is commonly established in Australian cities which is suitable to mitigate traffic congestion in cities as most of the congestions only occur in the town centers, where the usage of public transport should be encouraged. A few demand related and behavior survey has been found in literature which had been conducted in some cities in Australia: Canberra, Adelaide, and Melbourne. The results of those case studies are discussed in brief in the following section.

\subsection{Behavior and Demand Case Studies in Canberra, Adelaide} and Melbourne. P\&R strategies have evolved in Australian Capital Territory (ACT) when in 2004 ACT Government has recognized the need to develop a sustainable transport plan [12]. This plan chiefly focused on transport demand management and the objective was to attain a sustainable future transport system to uphold the values of living and working in Canberra by its citizens. ACT P\&R facilities are mostly allocated, surface car parks close to the bus interchanges in the town centers which have approximately 200 spaces in total or surface car parks at a number of group centers. Snowy Mountains Engineering Corporation (SMEC) Australia conducted a travel demand survey in Canberra to gather an insight of the travel pattern of $\mathrm{P} \& \mathrm{R}$ users of Canberra [12]. Results from the survey indicated that $98 \%$ of the respondents park their cars and then ride the bus for the large part of their journey and $73 \%$ of the respondents switched from car. Issues such as lack of sufficient bus services, lack of safety of vehicles and people, crowded buses, 
and misuse of $\mathrm{P} \& \mathrm{R}$ system have been identified during the demand survey.

A research study in Adelaide captured travel behavior changes of the users facilitated by the then (March, 2010) newly established P\&R facility at Adelaide Entertainment Centre (AEC) P\&R facility (on the fringe of Adelaide) [13]. The results from the survey showed that $29.8 \%$ P\&R users have previously driven to the city but now use car-mass transit combination (i.e., $29.8 \%$ car users shifted to P\&R scheme). But there was a greater concern in the negative results found which showed that $82.3 \%$ of previous entire journey public transport users now travel part of the way by car. In essence, P\&R facility at AEC center has facilitated an increase of vehicles on the road network and there was rise in Vehicle Kilometers travelled (VKT) for both car and overall transport network.

In Melbourne, the public transport accounts for only $10 \%$ of all travels in Metropolitan Melbourne, which has been significantly and historically lower against comparable cities such as Sydney, Toronto, and Montreal [14]. Victorian Government introduced a levy on public and private car parking spaces within the Melbourne city and adjacent inner city in January 2006 to encourage the public transport use and discourage the use of private and public vehicle on road [15]. In 2006, a total of 36,500 parking spaces were available for travelers to use at both regional and metropolitan railway stations in Victoria [16]. But the demand exceeded the supply by $40 \%$. In response to these excess demand, Victorian State Government committed to provide additional $5000 \mathrm{car}$ parking spaces in 2006 at railways stations in regional and metropolitan rail network. As a step towards fulfilling the commitment, there was up gradation at seven stations which delivered additional 580 car parking spaces for commuters. A survey conducted at seven upgraded stations showed that $36 \%$ of car drivers shifted to public transport and 29\% new users were added (who did not make similar trip prior to the up gradation).

Besides, another survey conducted in 2003 at Surrey Hills Railway Station [17] revealed that if the P\&R facility is full upon arrival, only $4 \%$ of drivers would drive to the destination while $48 \%$ prefer parking in a nearby street and only $5 \%$ would drive to the destination if the parking facility is closed while $46 \%$ would park in nearby street. Aforementioned survey results from literature have proved the greater demand of P\&R in Melbourne.

Despite the array of positive and negative results, there is no study to systematically analyze the effectiveness of $P \& R$ site on the commuters' travel mode change as well as the increase of public transport mode share. This paper will entail a survey case study at $\mathrm{P} \& \mathrm{R}$ facilities in Metropolitan railway stations and Doncaster bus terminal in Melbourne to explore the travel mode change behavior of P\&R users. This would help making effective decisions to plan for the future $\mathrm{P} \& \mathrm{R}$ facilities improving sustainability level of the entire transport infrastructure system.

2.3. Behavior Modeling for $P \nLeftarrow R$. A number of works have been conducted on the modeling of $\mathrm{P} \& \mathrm{R}$ behavior of commuters. Some models are proposed for single mode
TABLE 1: Survey locations.

\begin{tabular}{lcc}
\hline $\begin{array}{l}\text { Survey locations } \\
\text { (in Melbourne) }\end{array}$ & $\begin{array}{c}\text { Distance from } \\
\text { CITY }(\mathrm{km})\end{array}$ & $\begin{array}{c}\text { Available parking } \\
\text { space }\end{array}$ \\
\hline Doncaster & 18 & 400 \\
Glen Waverley & 24 & 340 \\
East Malvern & 14 & 676 \\
Blackburn & 22 & 112 \\
\hline
\end{tabular}

transportation network while some are present on multimodal transportation network.

A variational inequality (VI) formulation for the modeling of $\mathrm{P} \& \mathrm{R}$ services on multimodal transport network was proposed by Li et al. where they have incorporated parking behavior of auto commuters, elastic travel demand [18]. This work has been extended by Meng and Liu in 2012 where they have dealt with bus-based P\&R system in conjunction with congestion pricing scheme [8]. In their work, network equilibrium flow problem has been formulated where users' travel behaviors were assumed to follow probit-based Stochastic User Equilibrium (SUE).

\section{Methodology}

Factors affecting the choice of $\mathrm{P} \& \mathrm{R}$ and the extent of its effectiveness on how they affect the travel mode change behavior of commuters most were explored through a survey of $\mathrm{P} \& \mathrm{R}$ users at different metropolitan railway stations. The main objective of this study was to investigate the key factors in the mode change behavior of $P \& R$ users. Based on a survey of $\mathrm{P} \& \mathrm{R}$ users at different stations in Melbourne, we aim to gain a better understanding of the functioning of $P \& R$ and mode change behavior of $P \& R$ users. The details of the survey methodology are explained in the following subsections.

3.1. Survey Procedure. An intercept interview approach was used at three specific railway stations and a designated bus P\&R facility in Melbourne as specified in Table 1. Survey stations locatios were reasonablly chosen to approach more P\&R users. Participants were randomly selected when they alight from the train and are interviewed. 143 participants were surveyed and they completed the entire questionnaire.

There were three criteria chosen to select unbiased sample responses. These were that the respondent was (1) using P\&R site on the day of survey, (2) not a tourist and (3) 18 years old and over. Criteria (1) and (2) ensure that respondents are actually using P\&R service and are aware of the scheme.

3.2. Questionnaire. The questionnaire was comprised of two major components: (a) revealed preference (RP) questions and (b) stated preference (SP) questions. The RP part contains trip based questions which revealed information about the current travel behavior, previous mode of travel, and perspectives on the current transport related issues.

An orthogonal fractional factorial design using the SPSS was generated, consisting of nine SP scenarios in total. Each SP scenario contain three choices of transport modes (i.e., car, 


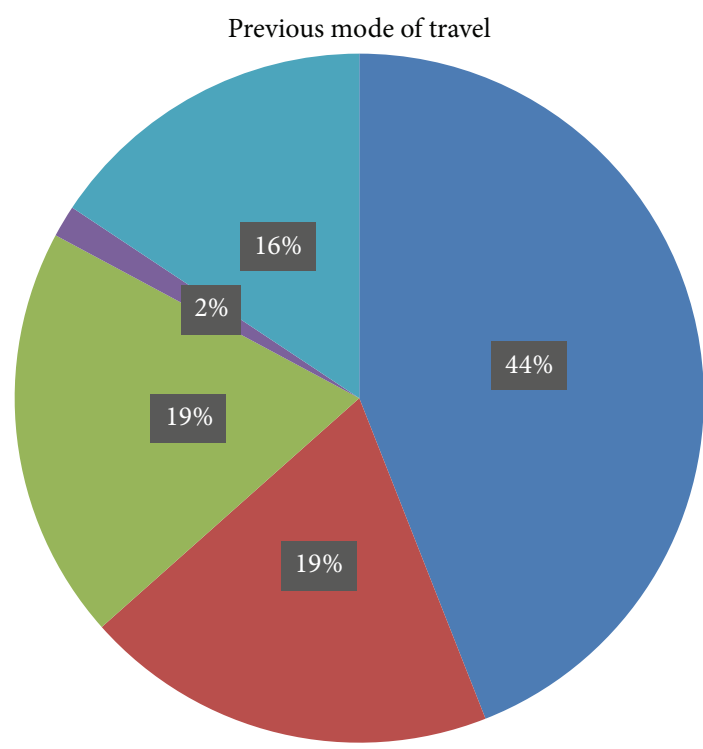

Reasons of shifting to P\&R from previously driving mode

Drove
PT only
Always P\&R

Bicycle
Did not make similar trip

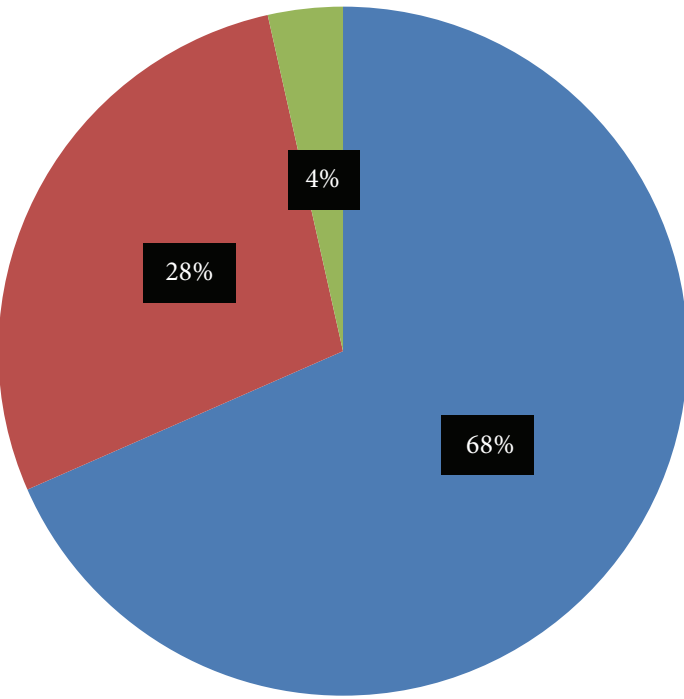

Convenient

Cheaper

Less trip time

Figure 1: Previous travel mode and reasons of shifting.

public transport only, and $\mathrm{P} \& \mathrm{R}$ ) and three variables each assigned with three different attribute levels are selected as factors influencing commuters' decision of travel mode choice: (a) parking fare in city $(\$ 10, \$ 20, \$ 40)$; (b) public transport only travel time (40 $\mathrm{min}, 60 \mathrm{~min}$, and $90 \mathrm{~min}$ ); (c) transfer time at $\mathrm{P} \& \mathrm{R}$ stations ( $5 \mathrm{~min}, 10 \mathrm{~min}$, and $20 \mathrm{~min}$ ).

In addition there were questions relating to sociodemographic characteristics (e.g., age, gender, annual income, education, employment status, and car ownership). Surveys were conducted in April-May, 2014, and during weekdays from $4.30 \mathrm{pm}$ to $6.30 \mathrm{pm}$. The afternoon period is chosen for conducting the survey to avoid the morning rush hour when commuters remain in a hurry not to miss their train/bus. The survey questionnaire took approximately 10 minutes to complete. To increase the response rate, each eligible participant was provided AUS $\$ 10$ gift voucher as an incentive.

3.3. Survey Data. Participants were first asked a few questions on their trip origin and destination which revealed the information on their travel purpose, how far they are travelling to destination from $P \& R$ facility, and their frequency of using $\mathrm{P} \& \mathrm{R}$ on each week. Each of the questions related to trip consisted of five alternative options for respondents to choose from.

A number of questions about past and current travel habits were also asked. For example, participants stated which modes they used to travel to their destination prior to starting use P\&R mode (they could choose various travel mode options including the answer "did not make similar trip before") and the reasons behind choosing P\&R compared to other possible options (they could select a number of reasons for their choice of $\mathrm{P} \& \mathrm{R}$ ). The responses to this query suggested that a greater portion of people have shifted to
P\&R mode from driving mode (44\%) and the reasons for choosing P\&R was mostly the ease and convenience of using $\mathrm{P} \& \mathrm{R}(68 \%)$ which includes no traffic congestion, no parking at work, infrequent bus time table from home/trip origin, and convenience of reading books or official documents in transit vehicle. Although not significant, there is still some abstraction from public transport users, who used public transport all the way to their destination and now shifted to a part of their travel by car to use P\&R site (19\%). The results from the survey are depicted in Figure 1.

In addition, participants were asked if, upon arrival at the P\&R site, they find no parking space is available, what they would do and the majority of commuters were inclined to park on the street nearby as it is clear from Figure 2.

Respondents' general experience of public transport service, $\mathrm{P} \& \mathrm{R}$ facility, and the traffic conditions in Melbourne were explored using a five-point Likert scale where low numbers indicated negative experiences. Participants were then asked nine SP experimental questions with varying parking fare in city, travel time taken by transit vehicle, and transfer time at P\&R stations to force choices among three travel modes: driving, public transport only, and P\&R mode. The SP nine scenarios are outlined in Table 2.

Finally, respondents were asked a series of questions requesting demographic information, which included the respondent's gender, age, occupation, origin post-code, numbers of cars they have access to, and annual income range.

\section{Results and Analysis}

The survey results have been analysed to explore the current behavior, frequency of travel, reasons of choosing P\&R over other modes, and individuals' opinion about a range of 
TABLE 2: Nine stated preference choice scenarios.

\begin{tabular}{lccc}
\hline Scenarios & $\begin{array}{c}\text { Parking } \\
\text { fare (\$) }\end{array}$ & $\begin{array}{c}\text { Travel time by public } \\
\text { transport alone (min) }\end{array}$ & $\begin{array}{c}\text { Transfer time at } \\
\text { P\&R station (min) }\end{array}$ \\
\hline 1 & 40 & 90 & 5 \\
2 & 10 & 60 & 20 \\
3 & 40 & 40 & 20 \\
4 & 10 & 90 & 10 \\
5 & 20 & 90 & 20 \\
6 & 40 & 60 & 10 \\
7 & 20 & 60 & 5 \\
8 & 20 & 40 & 10 \\
9 & 10 & 40 & 5 \\
\hline
\end{tabular}

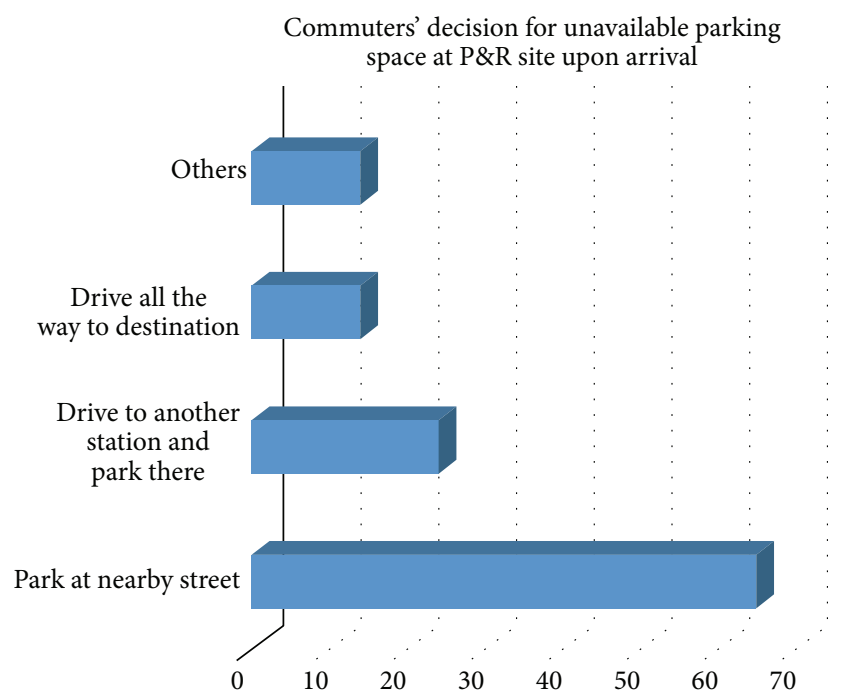

FIgURE 2: Commuters' decision upon no parking space at P\&R site.

transport related and $\mathrm{P} \& \mathrm{R}$ facility related issues. Commuters personal attitude response rating is analyzed which suggests that convenience of the $\mathrm{P} \& \mathrm{R}$ site, public transport service satisfaction, and transfer time at P\&R facility were the most answered positive answers with Likert scale 4 as shown in Figure 3.

Multinomial logistic regression analysis has been used for nine scenarios of SP experiments. In the literature, logistic regression is used to describe and test hypotheses about relationships between a categorical outcome variable and one or more categorical or continuous predictor variables [19]. There has been use of logistic regression in literature for different types of behaviorial and decision analysis [20]. Multinomial logistic regression was used to derive P\&R access staion choice model. It should be noted that in order to derive the probability function for the travel mode choice, a distributional function of the random error component needs to be assumed. We assumed that the error term follows the Independent and Identical Gumbel Distribution (IID Gumbel).

In this study, our response variable is "Choice" which is of three outcomes of choice of travel mode: drive, public

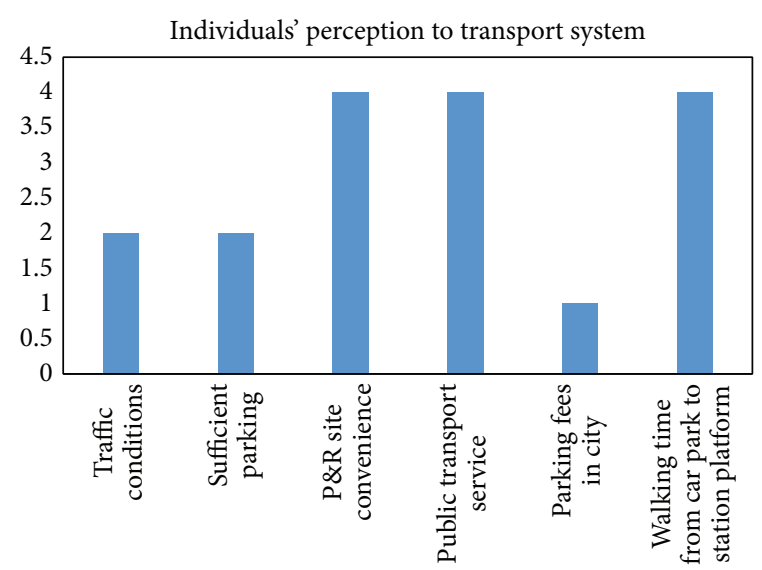

FIGURE 3: Individuals' response to transport system.

transport only, and P\&R mode. The multinomial logistic regression is a suitable technique to use because it is developed to model nominal outcome variables, in which the log odds of the outcomes are modeled as a linear combination of the predictor variables. In this model, the logit is the natural logarithm of the odds or the likelihood ratio that dependent variable is $Y_{i}=m$ (choosing a particular mode $m, m=1,2$ ) as opposed to $Y_{i}=3$ (choosing P\&R mode). The probability $P_{r}$ of a particular choice of travel mode is given by

$$
\begin{aligned}
& P_{r}\left(Y_{i}=3\right) \\
& \quad=\frac{1}{1+\sum_{j=1}^{2} \exp \left(\alpha+\beta_{1 j} X_{1}+\beta_{2 j} X_{2}+\beta_{3 j} X_{3}\right)} \\
& P_{r}\left(Y_{i}=m\right) \\
& \quad=\frac{\exp \left(\alpha+\beta_{1 m} X_{1}+\beta_{2 m} X_{2}+\beta_{3 m} X_{3}\right)}{1+\sum_{j=1}^{2} \exp \left(\alpha+\beta_{1 j} X_{1}+\beta_{2 j} X_{2}+\beta_{3 j} X_{3}\right)},
\end{aligned}
$$

where $\alpha$ is the intercept; $X_{r}$ is the independent variables; $r=$ $1,2,3 ; \beta_{r j}$ is corresponding coefficients; $j$ is refer to different travel mode $j=1,2,3$. In multinomial logistic regression, the ratio of the probability of outcome $j=m$ to that of outcome $j=k$ is called risk ratio $\left(\mathrm{RR}_{m}\right)$. In this paper $k=3$.

4.1. Factors Affecting P\&R Users' Choice. A statistical analysis has been carried out to investigate the factors affecting P\&R users' choice of travel mode. The factors analyzed to investigate the effects on choice of $\mathrm{P} \& \mathrm{R}$ are transfer time at P\&R site, travel time by public transport, parking fare, traffic conditions, and so forth.

4.2. Parking Fare and Traffic Congestions in City. RP data has been utilized to analyze the effects of parking fare as well as the effects of traffic congestion on individuals' travel mode choice which is shown in Table 3.

Likewise to congestion pricing schemes [21-25], high parking fare in city does have impacts on travelers' decision of travel mode. The extremely high parking costs in the city make commuters choose P\&R (61.6\%) over driving 
TABLE 3: Effects of parking fare and traffic congestion on choice of mode.

\begin{tabular}{|c|c|c|c|}
\hline & Public transport only & Driving & $\mathrm{P} \& \mathrm{R}$ \\
\hline \multicolumn{4}{|c|}{ Parking fare vs. Choice } \\
\hline Extremely high & $33.7 \%$ & $4.7 \%$ & $61.6 \%^{*}$ \\
\hline Low & $0.0 \%$ & $0.0 \%$ & $100 \%^{*}$ \\
\hline \multicolumn{4}{|c|}{ Traffic congestion vs. Choice } \\
\hline Extremely congested & $4.3 \%$ & $0.0 \%$ & $95.7 \%^{* *}$ \\
\hline Not congested at all & $0.0 \%$ & $100 \%{ }^{* *}$ & $0.0 \%$ \\
\hline
\end{tabular}

Note. ${ }^{*} p<0.05$ and ${ }^{* *} p<0.0001$.

alone (4.7\%). On the other hand, lower parking fares in city also make commuters more inclined to take P\&R (100\%) when it becomes the concern of traffic congestions on road and especially in and around city. Traffic congestion leaves only two possible options for travelers to choose: driving and P\&R. In case of extremely high traffic congestions, 95.7\% people would go for $\mathrm{P} \& \mathrm{R}$ while in congestion free situation, individuals are prone to driving (100\%).

4.3. Determinants of Mode Change Behavior. SP data are analyzed to determine the factors influencing mode change behavior of commuters. Their choice of travel modes was compared on the basis of predefined values for parking fare in city, travel time taken by public transport, and transfer time at $\mathrm{P} \& \mathrm{R}$ stations. These variables are determined by focusing the local context that is considered to influence on the choice of commuters' daily travel mode. Relationships among variables were tested empirically using the multinomial logistic regression in SPSS. The definitions of variables are outlined in Table 4 . The models for public transport only mode and driving alone mode are estimated relative to $P \& R$ mode baseline. Variables that were statistically significant are reported.

The reasons for individuals choosing public transport over P\&R mode and driving over P\&R mode are investigated. Parking fare in city does not have significant influence for individual commuters to choose public transport whereas travel time taken by public transport only mode and transfer time at $\mathrm{P} \& \mathrm{R}$ station is much more affecting the individuals to choose public transport alone for their whole part of journey. On the other hand, public transport travel time affects commuters to take P\&R mode over driving if the transit travel time becomes less. Transfer time at parking station is another sensitive factor affecting peoples' choice of transport mode. The estimation results of the comparison between public transport alone mode and P\&R mode as well as between driving alone mode and $\mathrm{P} \& \mathrm{R}$ mode are presented in Table 5.

4.4. Probability of Choosing Public Transport Only Mode over $P \circlearrowleft R$ Mode. Based on the $p$ values of the Likelihood Ratio Tests, four attribute levels from two factors were found to be significant $(p<0.0001)$. It should be noted that for the independent variables, 90-minute public transport travel time and 20-minute transfer time P\&R stations are taken as base variables. From results we can see that travel time
TABLE 4: Definitions of variables.

\begin{tabular}{lc}
\hline Variable name & Description \\
\hline Choice (public transport alone) & $Y_{i}=1$ \\
\hline Choice (drive) & $Y_{i}=2$ \\
\hline Choice (P\&R) & $Y_{i}=3$ (baseline) \\
\hline Parking fare in city & $\$ 10 ; \$ 20 ; \$ 40$ \\
\hline $\begin{array}{l}\text { Travel time taken by public transport alone } \\
\text { (when public transport is used for the whole }\end{array}$ & $\begin{array}{c}40 \mathrm{~min} ; 60 \mathrm{~min} ; \\
90 \mathrm{~min}\end{array}$ \\
$\begin{array}{l}\text { Trip) } \\
\text { walking time to the platform + waiting time for } \\
\text { the train) }\end{array}$ & $\begin{array}{c}5 \mathrm{~min} ; 10 \mathrm{~min} ; \\
20 \mathrm{~min}\end{array}$ \\
\hline
\end{tabular}

TABLE 5: Estimation results (relative to P\&R mode).

\begin{tabular}{|c|c|c|c|}
\hline Variables & $B$ & $\operatorname{Exp}(B)$ & Sig. \\
\hline \multicolumn{4}{|c|}{ Public transport only } \\
\hline \multicolumn{4}{|c|}{ (1) Public transport travel time (PTTT) } \\
\hline $40 \mathrm{~min}$ & 1.724 & 5.605 & .000 \\
\hline $60 \mathrm{~min}$ & .994 & 2.702 & .000 \\
\hline $90 \mathrm{~min}$ & Base & & \\
\hline \multicolumn{4}{|c|}{ (2) P\&R transfer time (P\&RTRT) } \\
\hline $5 \min$ & -1.710 & .117 & .000 \\
\hline $10 \mathrm{~min}$ & -1.008 & .247 & .000 \\
\hline $20 \mathrm{~min}$ & Base & & \\
\hline Intercept & -1.736 & l & .000 \\
\hline \multicolumn{4}{|c|}{ Driving only } \\
\hline \multicolumn{4}{|l|}{ (1) Parking fare } \\
\hline$\$ 10$ & 2.459 & 11.696 & .000 \\
\hline$\$ 20$ & 1.165 & 3.206 & .000 \\
\hline \multicolumn{4}{|c|}{ (2) Public transport travel time (PTTT) } \\
\hline $40 \mathrm{~min}$ & -.583 & .558 & .023 \\
\hline $90 \mathrm{~min}$ & Base & & \\
\hline \multicolumn{4}{|c|}{ (3) P\&R transfer time (P\&RTRT) } \\
\hline $5 \mathrm{~min}$ & -.996 & .366 & .000 \\
\hline $10 \mathrm{~min}$ & -.437 & .646 & .057 \\
\hline $20 \mathrm{~min}$ & Base & & \\
\hline Intercept & -2.415 & 1 & .000 \\
\hline Cox\&Snell R2 & & .216 & \\
\hline
\end{tabular}

taken by public transport and transfer time at $\mathrm{P} \& \mathrm{R}$ station are the only significant factors impacting the choice behavior of public transport mode only over P\&R mode. Parking fare being insignificant are omitted from the model of probability of choice of public transport alone mode over probaility of choosing P\&R mode.

The risk ratio (RR) for 60-minute (relative to 90 minute) travel time is greater than one $(\mathrm{RR}=2.702)$ indicating that the likelihood of choosing public transport only mode is more than choosing P\&R mode. For 40 min PTTT relative to $90 \mathrm{~min}$ PTTT, the relative chance for preferring public transport only to $\mathrm{P} \& \mathrm{R}$ would be expected to increase by a factor of 5.605 given the other variables in the model are held constant. In other words, commuters with 40 min PTTT 
are more likely than commuters with 60 min PTTT to prefer public transport only to $\mathrm{P} \& \mathrm{R}$.

On the other hand, the transfer time at $P \& R$ station is negatively influencing travelers' decision of choosing public transport only mode as compared to $\mathrm{P} \& \mathrm{R}$ mode. The coefficients for 5 minutes (coefficients, -1.710) and 10 minutes (coefficients, -1.008) indicate that the decision of travelers choosing public transport negatively declines over the decision of chooing P\&R mode. Therefore, in case of 5 minutes and 10 minutes transfer time at $\mathrm{P} \& \mathrm{R}$ stations, there are $88.3 \%(\mathrm{RR}=.117)$ and $75.3 \%(\mathrm{RR}=.247)$, respectively, less likely to choose public transport only than $\mathrm{P} \& \mathrm{R}$ mode.

4.5. Probability of Choosing Driving Alone over P\&R Mode. Based on the $p$ values of the Likelihood Ratio Tests, five attribute levels from three factors were found to be significant $(p<0.05)$. It should be noted that for the independent variables, $\$ 40$ parking fare; 90 -minute public transport travel time; and 20-minute P\&R station transfer time are taken as base variables. From results we can see that parking fare in the city; travel time taken by public transport, and transfer time at $P \& R$ station are the significant factors impacting the choice behavior of driving alone over P\&R mode.

In the case parking fare in city becomes $\$ 10$ per day, travelers are more inclined to drive to city rather than choosing $\mathrm{P} \& \mathrm{R}$ mode $(\mathrm{RR}=11.696)$. If the parking fare in city a bit more (\$20 per day) but relatively lower than base price ( $\$ 40$ per day) still there is likeliness of choosing driving $(\mathrm{RR}=3.206)$ to city over $\mathrm{P} \& \mathrm{R}$ mode.

On the other hand, this likeliness of choosing driving only over P\&R mode decreases in case of less public transport travel time (40 minutes relative to 90 minutes) as it is observed from the results negatively declining interest in travelers' choosing driving (coefficients, -.583). This is also clear from $\mathrm{RR}=.558$, for $40 \mathrm{~min}$ PTTT relative to $90 \mathrm{~min}$ PTTT; the relative chance for preferring driving only to P\&R would be expected to decrease by a factor of 442 given the other variables in the model are held constant. In other words, commuters with 40 min PTTT are less likely than commuters with 90 min PTTT to prefer driving only to P\&R.

The transfer time at $P \& R$ station is another negative factor influencing the decision of choosing driving comparing to P\&R mode. The multinomial logit for $5 \mathrm{~min}$ P\&RTRT relative to $20 \mathrm{~min}$ P\&RTRT is 996 units lower for driving only relative to $\mathrm{P} \& \mathrm{R}$ given all other predictor variables in the model are held constant. In other words, commuters with $5 \mathrm{~min}$ P\&RTRT are less likely than commuters with 10 min P\&RTRT (coefficients, -.437) to prefer driving only to P\&R mode. Therefore, the network context of the PNR should be further extended by considering some practical issue, for example, on survey methods [26], considering traffic flow dispersion $[27,28]$ or/and the travel time perception errors [29-32].

\section{Conclusions}

This paper explored the mode change behavior of P\&R users. Based on survey data on P\&R users at different stations car park and bus terminals in Melbourne, the choice behavior of mode change of $P \& R$ users is investigated. Multinomial logistic regression on SPSS was used in this study to estimate the models for public transport only mode and driving mode with a reference $P \& R$ mode.

This study identified that public transport travel and transfer time at $\mathrm{P} \& \mathrm{R}$ stations are impacting factors when choosing public transport only mode over P\&R mode, of which lower public transport travel time factor increases the probability of choosing public transport only mode for the whole part of the journey while lower transfer time are much convincing factors for travelers to choose $\mathrm{P} \& \mathrm{R}$ mode over public transport only mode.

This paper also showed that lower parking fare in city is positively influencing factor for commuters to opt for driving all the way rather than choosing P\&R mode while lower public transport travel time and transfer time at $\mathrm{P} \& \mathrm{R}$ stations have higher likelihood of choosing $\mathrm{P} \& \mathrm{R}$ mode over driving.

As the population growth in Melbourne is recently in higher trends, it will become the largest populated city of Australia within next 50 years. Thus the mode change behaviours of commuters would influence substantially in deciding on city's transportation system. Therefore, governments need to consider holistically when planning for transportation infrastructure. The estimated models and results of analysis of this paper could be used in future plan for the P\&R scheme and the design of such infrastructure.

\section{Conflict of Interests}

The authors declare that there is no conflict of interests regarding the publication of this paper.

\section{Acknowledgments}

The research was supported by SEED Fund in the Faculty of Engineering at Monash University. The authors would also like to thank Terry Chan for his help on designing a part of the questionnaire; Justin Sprigg, Karan Chandra, and Xiaoying Cao for their help on the survey data collection. Any omissions or errors are the responsibility of the authors.

\section{References}

[1] J. Manns, Park-and-Ride: Politics, Policy and Planning, Town and Country Planning Association, 2010.

[2] H. Qin, H. Guan, and Y.-J. Wu, "Analysis of park-and-ride decision behavior based on decision field theory," Transportation Research Part F: Traffic Psychology and Behaviour, vol. 18, pp. 199-212, 2013.

[3] Z. Liu and Q. Meng, "Bus-based park-and-ride system: a stochastic model on multimodal network with congestion pricing schemes," International Journal of Systems Science, vol. 45, no. 5, pp. 994-1006, 2014.

[4] N. S. Rosli, S. Adnan, S. Adibah Alyia et al., "A theoretical review on sustainable transportation strategies: the role of park and ride facility as a generator of public transport mode shift," in Proceedings of the 23rd EAROPH World Congress the Eastern Regional Organisation for Planning and Human Settlement, 2012. 
[5] E. C. Noel, "Park-and-ride: alive, well, and expanding in the United States," Journal of Urban Planning and Development, vol. 114, no. 1, pp. 2-13, 1988.

[6] F. Aros-Vera, V. Marianov, and J. E. Mitchell, "p-hub approach for the optimal park-and-ride facility location problem," European Journal of Operational Research, vol. 226, no. 2, pp. 277285, 2013.

[7] D. Banister, "Sustainable urban development and transport-a Eurovision for 2020," Transport Reviews, vol. 20, no. 1, pp. 113$130,2000$.

[8] Q. Meng and Z. Liu, "Impact analysis of cordon-based congestion pricing on mode-split for a bimodal transportation network," Transportation Research Part C: Emerging Technologies, vol. 21, no. 1, pp. 134-147, 2012.

[9] S. Meek, S. Ison, and M. Enoch, "Role of bus-based park and ride in the UK: a temporal and evaluative review," Transport Reviews, vol. 28, no. 6, pp. 781-803, 2008.

[10] W. H. K. Lam, N. M. Holyoak, and H. P. Lo, "How park-and-ride schemes can be successful in Eastern Asia," Journal of Urban Planning and Development, vol. 127, no. 2, pp. 63-78, 2001.

[11] P. Barter, ark-and-Ride Comparison: Vancouver, Melbourne and Perth. Reinventing Parking, 2010, http://www.reinventingparking.org/2010/12/park-and-ride-comparison-vancouver.html.

[12] A. Smec, "Park and Ride Strategy for the Australian Capital Territory," Reference:3002128, 2007.

[13] N. Wiseman, J. Bonham, M. Mackintosh, O. Straschko, and H. $\mathrm{Xu}$, "Park and ride: an adelaide case study," Ride: an Adelaide case study, vol. 21, no. 1, pp. 39-52, 2012.

[14] Public Transport Users Association, 2010, http://www.ptua.org .au/.

[15] P. Hamer, G. Currie, and W. Young, Exploring Travel and Parking Impacts of the Melbourne CBD Parking Levy, Planning and Transport Research Centre (PATREC), 2009.

[16] P. Hamer, "Analysing the effectiveness of park and ride as a generator of public transport mode shift," Road \& Transport Research, vol. 19, no. 1, pp. 51-107, 2010.

[17] J. Palmer and N. Donnison, "The influence of parking on public transport use," Working Paper, Department of Infrastructure, Melbourne, Australia, 2003.

[18] Z.-C. Li, W. Lam, S. Wong, D.-L. Zhu, and H.-J. Huang, "Modeling park-and-ride services in a multimodal transport network with elastic demand," Journal of the Transportation Research Board, vol. 1994, no. 1, pp. 101-109, 2007.

[19] C.-Y. J. Peng, K. L. Lee, and G. M. Ingersoll, "An introduction to logistic regression analysis and reporting," The Journal of Educational Research, vol. 96, no. 1, pp. 3-14, 2002.

[20] M. Johnson and K. Parrot, "A logistic regression analysis of factors affecting recycling behavior in apartment communities," Housing and Society, vol. 22, no. 3, pp. 41-52, 1995.

[21] Z. Liu, S. Wang, and Q. Meng, "Toll pricing framework under logit-based stochastic user equilibrium constraints," Journal of Advanced Transportation, vol. 48, no. 8, pp. 1121-1137, 2013.

[22] Z. Liu, S. Wang, and Q. Meng, "Optimal joint distance and time toll for cordon-based congestion pricing," Transportation Research Part B: Methodological, vol. 69, pp. 81-97, 2014.

[23] Q. Meng, Z. Liu, and S. Wang, "Optimal distance tolls under congestion pricing and continuously distributed value of time," Transportation Research Part E: Logistics and Transportation Review, vol. 48, no. 5, pp. 937-957, 2012.

[24] Z. Liu, Q. Meng, and S. Wang, "Variational inequality model for cordon-based congestion pricing under side constrained stochastic user equilibrium conditions," Transportmetrica A: Transport Science, vol. 10, no. 8, pp. 693-704, 2014.

[25] Z. Liu, Q. Meng, and S. Wang, "Speed-based toll design for cordon-based congestion pricing scheme," Transportation Research Part C: Emerging Technologies, vol. 31, pp. 83-98, 2013.

[26] X. Qu, S. Wang, and J. Zhang, "On the fundamental diagram for freeway traffic: A novel calibration approach for single-regime models," Transportation Research Part B: Methodological, vol. 73, pp. 91-102, 2015.

[27] Y. Bie, D. Wang, and H. Qi, "Prediction model of bus arrival time at signalized intersection using GPS data," Journal of Transportation Engineering, vol. 138, no. 1, pp. 12-20, 2011.

[28] Y. Bie, Z. Liu, D. Ma, and D. Wang, "Calibration of platoon dispersion parameter considering the impact of the number of lanes," Journal of Transportation Engineering, vol. 139, no. 2, pp. 200-207, 2013.

[29] Z. Liu, Y. Yan, X. Qu, and Y. Zhang, "Bus stop-skipping scheme with random travel time," Transportation Research Part C: Emerging Technologies, vol. 35, pp. 46-56, 2013.

[30] Q. Meng, Z. Liu, and S. Wang, "Asymmetric stochastic user equilibrium problem with elastic demand and link capacity constraints," Transportmetrica A: Transport Science, vol. 10, no. 4, pp. 304-326, 2014.

[31] Z. Liu and Q. Meng, "Distributed computing approaches for large-scale probit-based stochastic user equilibrium problems," Journal of Advanced Transportation, vol. 47, no. 6, pp. 553-571, 2013.

[32] Y. Yan, Z. Liu, Q. Meng, and Y. Jiang, "Robust optimization model of bus transit network design with stochastic travel time," Journal of Transportation Engineering, vol. 139, no. 6, pp. 625634, 2013. 


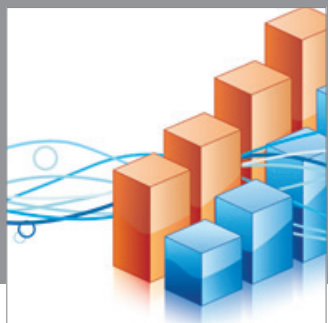

Advances in

Operations Research

mansans

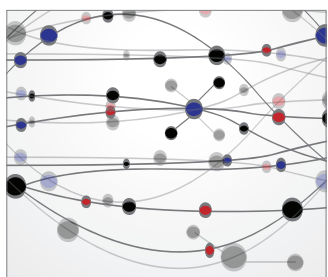

The Scientific World Journal
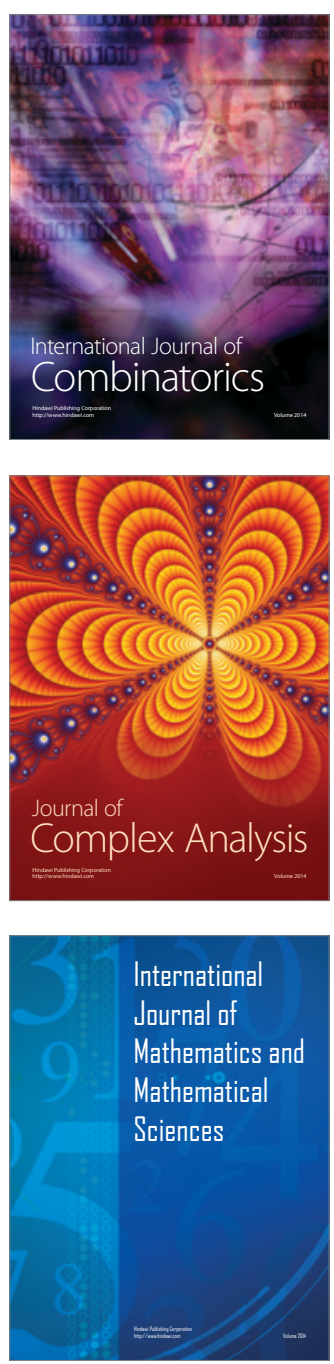
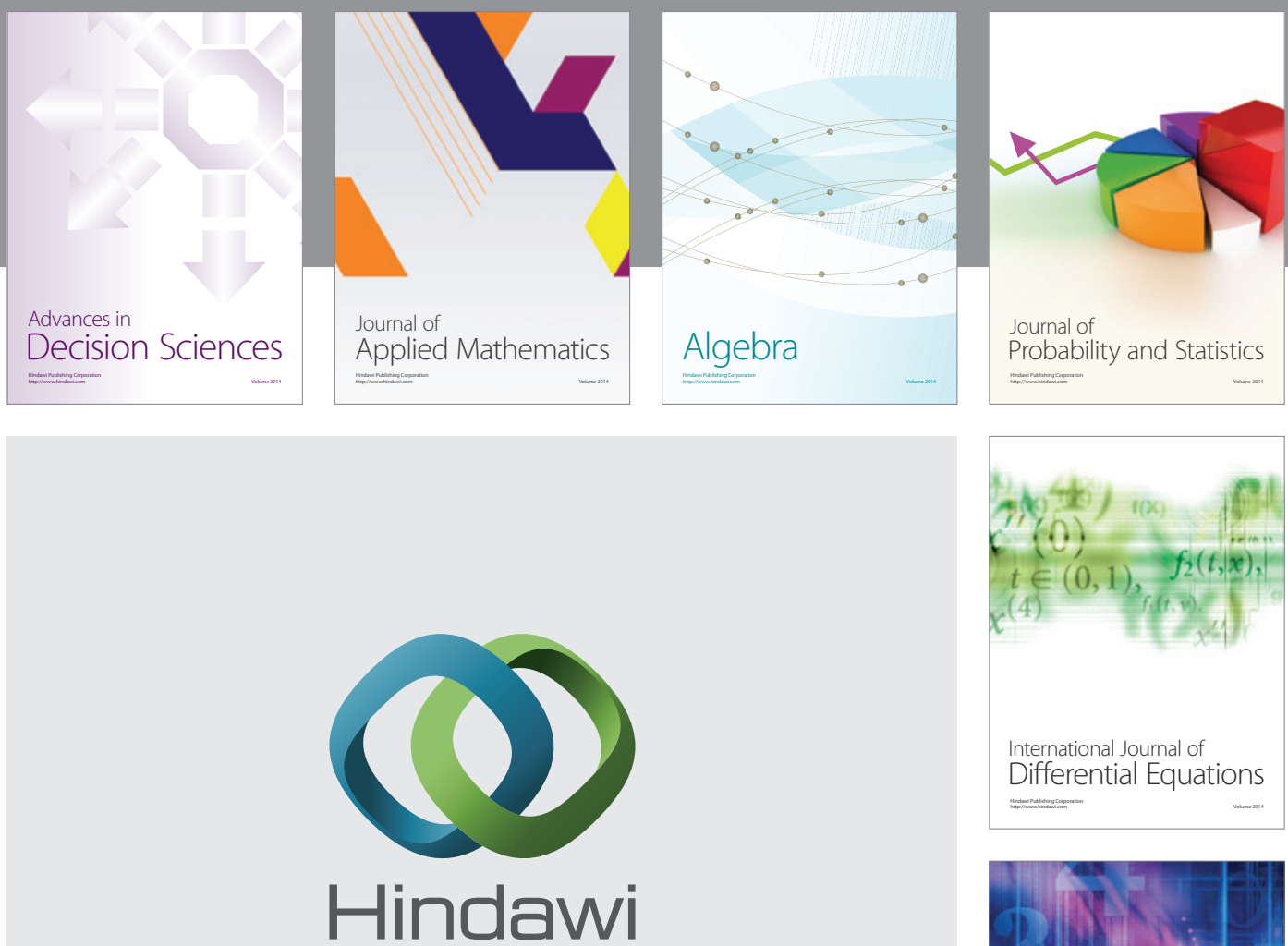

Submit your manuscripts at http://www.hindawi.com
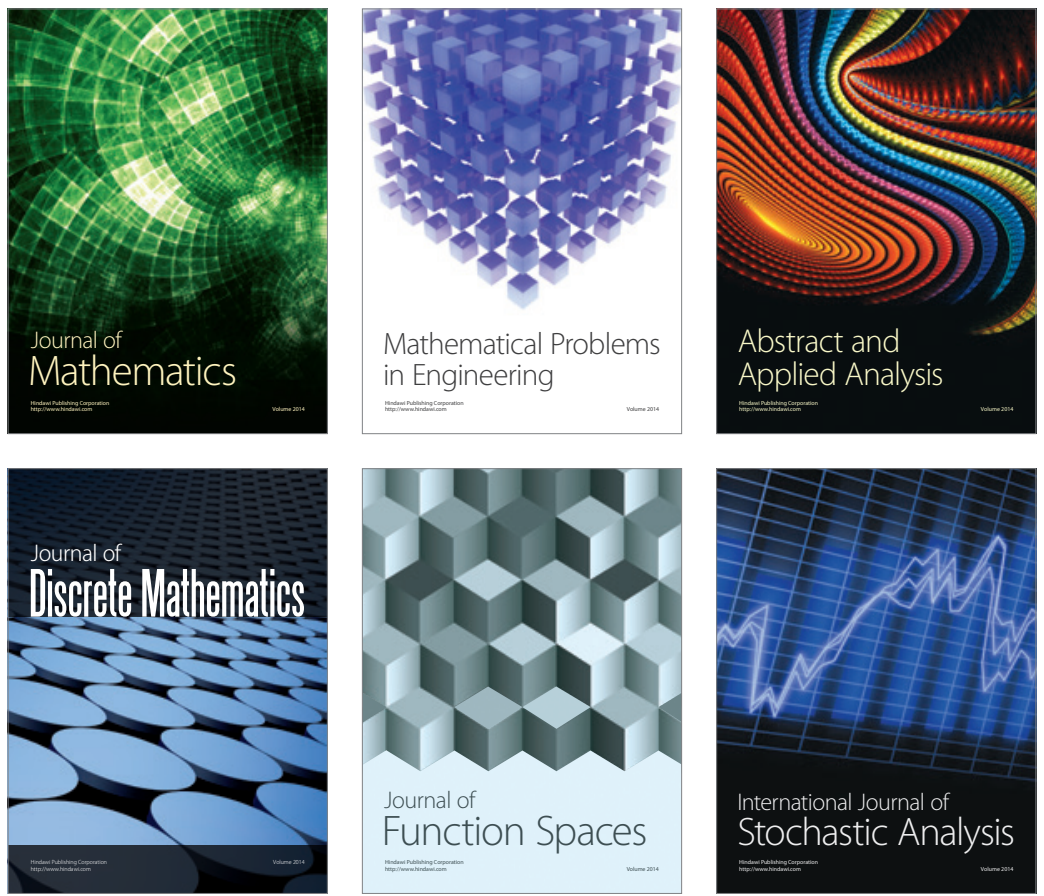

Journal of

Function Spaces

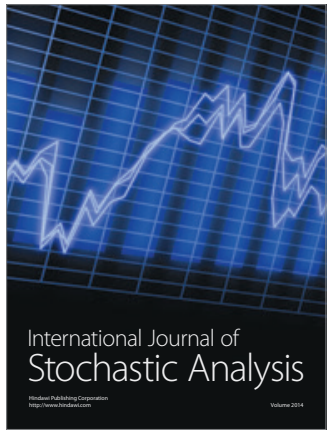

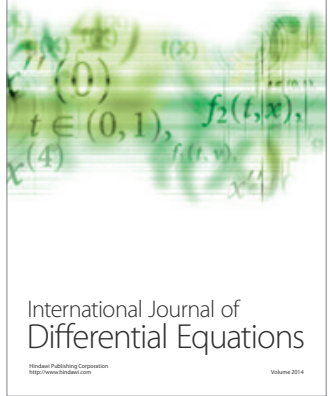
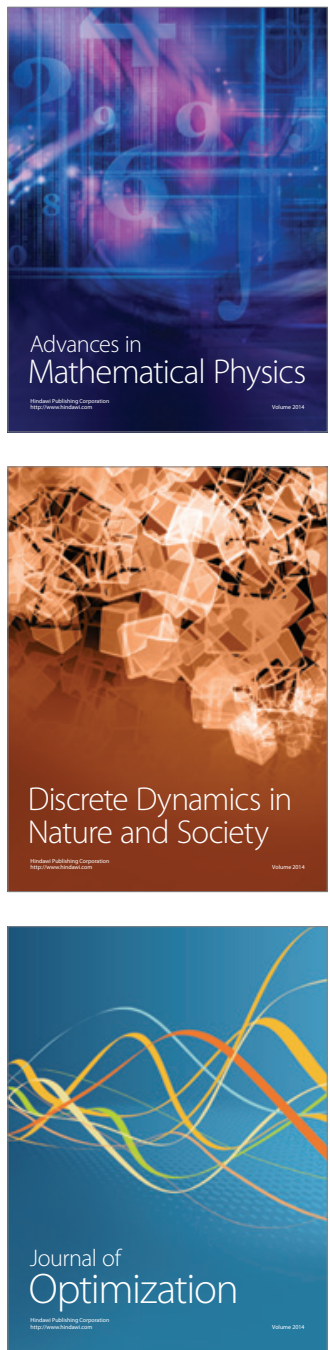